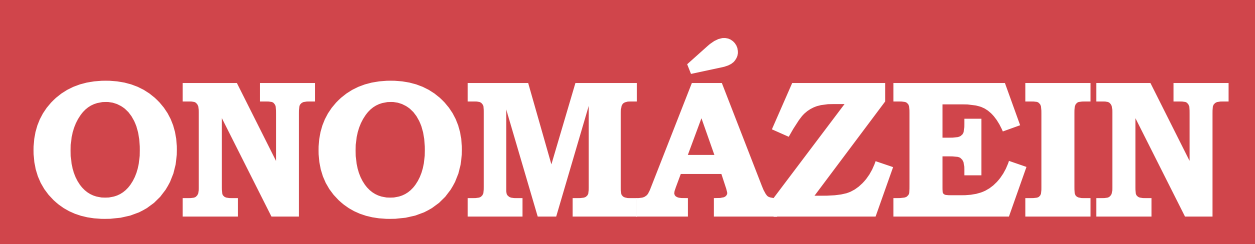

Revista de lingüística, filología y traducción
PONTIFICIA UNIVERSIDAD

\title{
La estrategia evidencial dizque en el español de Medellín, Colombia ${ }^{1}$
}

Dizque as evidential estrategy in

Colombian Medellin Spanish

\section{Róbinson Grajales}

Universidad de Antioquia / Universidad del Valle

Colombia

\section{(C) $($ (i) $\ominus$}

Róbinson Grajales: Escuela de Ciencias del Lenguaje, Facultad de Humanidades, Universidad del Valle, Colombia. | Correo electrónico: robinson.grajales@correounivalle.edu.co 


\section{Resumen}

En el español de América se han realizado varios estudios sobre la unidad dizque, en los cuales se ha descrito su significado evidencial. En este artículo se describe el uso de dizque como estrategia evidencial en el español de Medellín, Colombia. Tomando como referencia el corpus PRESEEA-Medellín, se analizaron los significados de esta unidad y su uso con respecto a las variables sociales definidas en el corpus. De esta manera, se estableció la polifuncionalidad de dizque, que tiene seis funciones en el español de Medellín: indicación de modalidad epistémica, fuente ajena imprecisa, discurso directo, discurso indirecto, marcación de elementos nominales y la indicación de modo de acceso cognitivo a la información que se presenta. En relación con las variables sociales, dizque tienden a usarlo menos las mujeres, los informantes de clase social alta y los de nivel educativo superior, lo cual está relacionado con que esta estrategia evidencial se considere más propia del registro informal.

Palabras clave: evidencialidad; pragmática; semántica; sociolingüística; dizque; español de Colombia.

\section{Abstract}

Several studies have been carried out on the so-called "dizque" unit in Latin-American Spanish, describing its evidential meaning. This article describes the use of "dizque" as an evidential strategy in Spanish spoken in Medellin, Colombia. Taking the PRESEEA-Medellín corpus as a reference, the meanings of this unit and its use with respect to the social variables defined in the corpus were analyzed. In this way, the polyfunctionality of dizque was established, and six functions in Medellin Spanish are proposed: epistemic modality, imprecise external source, direct discourse, indirect discourse, marking of nominal elements and the indication of mode of cognitive access to the information presented. Respect to social variables, it is proposed that women, upper class and higher education informants tend to use it less, which relates to the fact that this evidential strategy is thought to be more suited to the informal registry.

Keywords: evidentiality; Pragmatics; Semantics; Sociolinguistics; dizque; Colombian Spanish.

1 Este artículo se deriva de la tesis doctoral "Expresión de la evidencialidad en el español de MedeIlín”, la cual se realizó dentro del marco de la investigación Estudios sociolingüísticos de variación y cambio en el español hablado en Medellín, desarrollada entre 2011 y 2015 e inscrita en el CODI de la Universidad de Antioquia. Proyecto registrado en el Acta CODI 580 de 2010 bajo el código 32-2011. 


\section{Introducción}

Entre los estudios que se han realizado sobre dizque en el español de América se encuentra el de Magaña (2005), quien presenta la forma en que se ha transformado dice que en dizque. Después de desplegar el análisis sobre el proceso de gramaticalización de esta unidad, la autora concluye que este cambio va de lo concreto a lo abstracto, es decir, de un sintagma predicacional a una forma evidencial: dice que > dizque. Para Magaña (2005), las causas que motivan el cambio son diversas, pero entre ellas destaca la pérdida del sujeto, que se refuerza con un contenido pragmático: si no sé quién lo dijo, puedo dudar de su veracidad. La autora resume el camino que recorrió esta gramaticalización de la siguiente manera: Forma verbal plena y relativo que introduce completiva > Debilitamiento del sujeto, descarga de anaforicidad > Pérdida del sujeto > Univerbación de las formas dice y que, recarga de significado pragmático > Pérdida de marcas previas de negación e impersonalidad > Rigidización de la forma, puede aceptar otro relativo. De esta manera, dos formas pierden autonomía sintáctica y léxica y se funden en una sola.

En cuanto al abordaje diacrónico de dizque que hace la autora, se deja de lado en esta exposición porque aquí interesa principalmente el tratamiento que hace de dizque como evidencial. En este sentido señala que dizque actualmente tiene dos acepciones, una como sustantivo, acepción que aparece en el DRAE (2001) como "Dicho, murmuración, reparo", pero de la cual no se dan ejemplos, y la otra como adverbio. La autora solo considera la acepción de adverbio, conceptualizada como un marcador verbal, dado el peso pragmático que contiene. El uso de dizque como marcador pragmático evidencial indica la falta de certeza en una aseveración: "no me consta y lo pongo en duda". La autora remarca el hecho de que la frecuencia de uso de dizque en el español americano es notablemente más alta que en el español peninsular (50 casos en España y el resto en América de 271 en el CORDE; 3 casos en España y el resto en América de 254 en el CREA). La autora aporta algunos ejemplos del uso de esta unidad como marcador evidencial:

(1) Luciano era un cholito que había llegado a la capital dizque a estudiar.

(2) Ella quiso yopearlo como a los demás, pero, Lotario quería la plata, y al ver que ella no tenía el chen chen porque dizque se lo habían robado, le dijo que fueran a discutir el movi a su cuarto.

(3) Europa, la cuna de tantas teorías filosóficas, con el propósito dizque para bien del mundo, fallaron muchas de ellas.

(4) Pero parece que sí los regalan a todo el mundo -y eso que dizque que están en vías de extinción.

En estos ejemplos, tal como lo señala la autora, dizque tiene un uso "pragmatizado" en el cual ha dejado de ser "Io dicho por alguien" o "se dice algo" para convertirse en un marcador del 
verbo que resalta un determinado hecho y cuestiona su certeza, lo califica y lo valora desde una perspectiva subjetiva.

Este significado de valoración de la veracidad de la información muchos autores lo denominan modalidad epistémica (Landaburu, 2005; Bermúdez, 2006), para diferenciarlo de la evidencialidad propiamente dicha, que hace referencia a la fuente de la información. Incluso, estos mismos autores recomiendan delimitar estos dos campos y estudiarlos por separado. Magaña (2005), según lo que se puede ver en su análisis de dizque, incluye la modalidad epistémica dentro del campo de la evidencialidad. Aunque la autora no lo plantea de ninguna manera, podría decirse que dizque es una unidad que expresa simultáneamente la evidencialidad y la modalidad epistémica, y, tal vez, podrían estudiarse por separado, aunque estos dos campos están estrechamente relacionados en lenguas como el español, en las cuales no hay marcas obligatorias para ellos. Tomando como referencia el uso que la autora le atribuye a dizque en la actualidad ("no me consta y lo pongo en duda”), podría pensarse que sigue conservando su componente evidencial: "no me consta" como algo dicho por alguien o que se dice; a la vez que expresa, al mismo tiempo, la modalidad: "lo pongo en duda".

También para el español de México, Olbertz (2007) estudia el origen de esta unidad y describe su uso en el habla mexicana desde el punto de vista sintáctico y semántico. Esta autora concuerda con Magaña en que esta unidad se derivó de una forma apocopada de la tercera persona del singular del verbo dezir, y reconstruye el desarrollo sintáctico de diz(e) personal más la conjunción subordinante que a dizque, pero, contrario a lo que sostienen Company (2004, citada por Olbertz, 2007) y Magaña (2005), no considera que este haya sido un proceso de gramaticalización, sino de lexicalización, porque da como resultado un lexema y no un elemento gramatical. Desde el punto de vista semántico, según Olbertz (2007), se trata de un desarrollo del discurso indirecto no marcado a la proposición marcada por evidencialidad reportativa, con la cual se indica que la fuente de la información presentada es ajena al hablante. Y este significado, en algunos contextos, como lo explicará después la autora, se relaciona con la puesta en duda de la veracidad de lo que el hablante está diciendo, lo cual es lo más frecuente en el español de México según Olbertz (2007). Además, esta autora sostiene que este uso de dizque no se marca socialmente, sino más bien con respecto al registro, pues aparece sobre todo en contextos informales.

En cuanto a la sintaxis, Olbertz muestra que dizque modifica el complejo verbal y sus argumentos (todos los ejemplos son citados por Olbertz, 2007):

(5) Tomaron unos jarabes rarísimos para que la regla no les hiciera tanto daño, que dizque les daban unos dolores tremendos de cabeza.

Además, anota que cuando hay un sujeto léxico o pronominal puede estar sucedido por dizque o quedar incluido dentro de su alcance. Esto último lo ejemplifica de la siguiente manera: 
(6) Muy pronto nos vamos a ir de Santa María, que dizque la Narvarte es mucho mejor que esta colonia.

De acuerdo con su análisis, dizque puede modificar toda la oración o solamente un constituyente; en este último caso, dizque precede a la unidad lingüística que modifica.

(7) Dice don Toribio que [vino] dizque a comprar el pueblo.

(8) Jorge quiere poner aquí dizque su oficina.

De igual manera, en algunos casos, dizque se emplea para modificar las partes nucleares de los elementos referenciales, porque para referirse a los argumentos el hablante emplea predicados que marca por ser de fuente ajena, separando la predicación de la referencia, que normalmente son inseparables:

(9) Trajo un dizque compás marino, que resultó ser un visor de fotos.

En relación con el aspecto semántico, Olbertz (2007) explica que cuando dizque está modificando toda la oración indica que la fuente de la proposición es ajena al hablante, lo cual implica que el hablante no se responsabiliza de la veracidad de lo que está diciendo. En el caso de la modificación de los constituyentes, el uso de dizque casi siempre expresa una actitud de incredulidad con respecto al contenido proposicional. Por otro lado, cuando dizque modifica una cualificación otorgada anteriormente por otra persona, este tiene que ver con la adecuación de la cualificación, mas no con la veracidad; a esto Olbertz (2007) lo denomina “modificación metalingüística”. En estos casos, dizque expresa la convicción de la inadecuación del calificativo aplicado explicitando la intención irónica del hablante:

(10) Mira güey, desde secundaria teníamos un grupo dizque de beneficencia y esas jaladas.

Olbertz (2007) resalta que estos usos metalingüísticos también aparecen con sujetos de primera persona. En estos casos dizque se utiliza para marcar una cualificación falsa y puede anteceder o seguir a la oración:

(11) Soy como de la familia, dizque.

(12) Siempre tuvieron celos, dizque más me ocupaba de estos que de ellos.

La autora aclara que en estos ejemplos dizque no modifica una proposición, sino un enunciado atribuible a una(s) persona(s) específica(s), pues no sería lógico que el hablante recurriera a información de segunda mano para la descripción de una situación en la que participó.

En este estudio, la autora concluye que el uso del dizque en México ha aumentado y es utilizado para modificar constituyentes nominales, adverbiales y predicados de toda índole. Ade- 
más, dice que su valor básico es evidencial en el sentido de fuente ajena, pero se le atribuyen otros sentidos como, por ejemplo: la duda acerca de la veracidad, la adecuación de lo que se cita o la convicción de su falsedad. Olbertz (2007) aclara que este último sentido es muy subjetivo y solo se da cuando el alcance de dizque es muy reducido, lo cual valida la hipótesis, planteada en su estudio, de que cuanto más decrece el alcance más aumenta la subjetivización.

En general, los estudios sobre dizque en el español mexicano (Magaña, 2005; Olbertz, 2007; García Fajardo, 2009) coinciden en la explicación del origen y la evolución de los significados de esta unidad, así como en la constatación de que, siendo su significado básico la evidencialidad, en la actualidad su uso está asociado con sentidos referentes a la modalidad epistémica, con diferentes matices de significado dependiendo del contexto.

Por otra parte, Olbertz (2005), en su estudio sobre el uso de dizque en el español ecuatoriano en un contexto bilingüe en contacto con el quechua, ha mostrado que esta unidad se presenta con una alta frecuencia y que ha conservado su carácter reportativo (evidencial), siendo muy común su concurrencia con ciertos verbos exclusivamente:

(13) Entrando a la hacienda dizque pregunta cuál es el patrón.

(14) Si no me perdonas mátame que quiero morir en tus manos dizque dice.

(15) El patrón dizque dijo "almuerza la perra, almuerzas vos. Y sale la perra almorzando, te vas”.

Como se puede ver en estos ejemplos, dizque se combina la mayoría de las veces, según los datos aportados por la autora, con un verbo de comunicación como preguntar en el ejemplo (13) o el mismo decir en los ejemplos (14) y (15). A partir de los datos cuantitativos de su estudio, la autora afirma que decir es el verbo que más concurre con dizque: de 515 casos de dizque en narraciones, 287 están seguidos inmediatamente por una forma de decir, mientras que hay solo 19 casos seguidos por una forma de preguntar, contar, saludar u otro verbo de comunicación; de acuerdo con la autora, es mucho más frecuente la ocurrencia de las formas dice (181 casos) y dijo (63 casos):

(16) Dizque dice, "vea usted, camine dos días, de noche, camina dos días. La primer noche usted duerma en cualquier parte. Pero la segunda noche va encontrar una, un hueco grande, que es una cueva grande. Ay, ahí está cajones de plata pero que hay, este es lindas. Ahí hay lo que quiera plata".

(17) “Patrón se enoja conmigo" dizque dijo él.

(18) “(...) entonces que, que asome, que asome dé Ilamando" dizque dijo "dé Ilamando al patrón".

Como se puede observar en estos ejemplos, y en otros que aporta la autora pero que no se incluyen aquí, en todos los casos dizque + decir aparece en el contexto inmediato de discurso 
directo, como en (16), donde sirve para introducir el discurso directo; o en (17), donde aparece al final del discurso directo; o en (18), donde se introduce dizque dijo en la mitad de un fragmento de discurso directo. Otro dato importante que aporta Olbertz (2005) es que el verbo decir sin dizque en el contexto del discurso directo ocurre muy pocas veces en textos narrativos. De la relación entre la frecuencia de 86 de decir y la de 287 de dizque decir, concluye (aunque aclarando que de manera tentativa) que hay una tendencia hacia la obligatoriedad de dizque con decir en el contexto de discurso directo en textos narrativos.

Es importante resaltar que Olbertz (2005) hace un análisis sociolingüístico en el que observa la distribución del uso de dizque según el tipo de texto y la clase de hablantes. Para ello, compara la producción de dizque de hablantes bilingües con predominio quechua (BQ), bilingües con predominio español (BE) y monolingües de clase baja (MI), en textos narrativos y no narrativos. Los resultados presentados por la autora muestran que dizque se produce mucho más en los textos narrativos (88\%) que en los otros textos (7,8\%). Dentro de los textos narrativos, quienes producen más dizque son los informantes $\mathrm{M} I(34,8 \%)$, seguidos de los informantes BQ $(30,7 \%)$ y, por último, los informantes BE $(22,5 \%)$.

Este tipo de análisis es interesante, porque muestra que una estrategia evidencial está sometida a variación, la cual se da por factores lingüísticos y extralingüísticos. Esta manera de analizar la evidencialidad podría extenderse al estudio de otras estrategias evidenciales en comunidades de habla específicas.

En cuanto al español colombiano, se encuentra el estudio de Travis (2006), en el que muestra que dizque es usado como una estrategia principalmente evidencial y como un marcador de modalidad epistémica. En este sentido, para esta autora, su significado principal es el de indicar la fuente de la información y el sentido de duda se obtendría por una inferencia de acuerdo con el contexto, aunque este segundo sentido no sería inherente a la semántica de dizque. En esto esta investigadora concuerda con los otros estudios que se han presentado aquí, en el sentido de que dizque es un marcador evidencial que con el tiempo ha adquirido una interpretación de modalidad epistémica de acuerdo con el contexto. En esta dirección, se reafirma que esta unidad puede expresar los dos contenidos.

A partir de la combinación de datos orales y escritos, conversaciones y obras literarias, respectivamente, Travis (2006) afirma que dizque es más característico del habla informal, tanto en la oralidad como en la escritura; de ahí que trabajara, para el corpus escrito, con novelas en las que se empleara un estilo informal, o que por lo menos han sido escritas con la intención de acercarse a la oralidad. En una primera comparación de estos dos corpus de trabajo, la autora constata que en la escritura, a pesar de su intencional cercanía con la oralidad, la frecuencia de dizque es mucho más baja que en los datos orales (0.25 y 0.75 ocurrencias por cada 1000 palabras, respectivamente), lo cual refuerza la hipótesis de su uso preferente en el registro informal. 
En su análisis, Travis (2006) encontró cuatro funciones de dizque. La primera es la función de discurso referido, ya sea para introducir discurso directo o discurso indirecto, en la cual se introduce un enunciado que es atribuible a una persona específica o a un grupo de personas (los corchetes son del texto original):

(19) A: Pero qué te dicen.

[Qué te dicen]?

S: [Dizque], huy. Doña Carmen quiere bastante a Jaime.

(20) A: Ya me dicen -- dizque, si soy periodista.

... Ahorita, me dijeron, Me dijeron, dizque, que periodista, oyó.

La segunda es la que se podría denominar como la función de indicar una fuente ajena inespecífica (hearsay), en la cual no se reporta un acto de habla atribuible a un agente o a una fuente específica, sino que se indica que el contenido presentado procede de una fuente externa no especificada, que se podría interpretar como se dice que o dicen que, con el uso impersonal en este último caso:

(21) A: ... Por ejemplo, el a--- aquí el alcalde, Todo lo que ha hecho,

Y -- y ahorita, dizque ya lo están investigando.

Según la autora, estas dos funciones anteriores son mucho más frecuentes introduciendo cláusulas completas.

La tercera función, claramente diferenciada de las que se acaban de presentar, es la que la autora llama labeling, que no introduce oraciones completas como las anteriores, sino sintagmas nominales o preposicionales. No hace referencia a la fuente del contenido, solo indica que el término no es atribuible al hablante y podría interpretarse como lo que Ilaman:

(22) N: tengo uno, tengo dizque el capa, o algo así.

Y la cuarta es la función que expresa significados que son extensión de la duda, aunque la autora insiste en que la duda propiamente dicha es contextual, sobre los hechos referidos, que Travis (2006) denomina dubitativa, en la cual no se le atribuye el contenido de lo dicho a nadie. De hecho, en todos los casos, el hablante participa de la acción o el evento introducido por dizque, y se expresa una actitud (con diferentes matices de significado dentro de las extensiones que pueda tener la duda) sobre lo dicho como una falsa creencia, una meta inalcanzable o como una consecuencia de carácter incontrolable. Esto se puede ver en el siguiente ejemplo, en el que los hablantes son colombianos pero están hablando de México:

(23) ... lo primero que nos dice es: "No se vayan para el Distrito Federal, por favor". Pero fue como si nos hubieran dicho, "iVáyanse para el D.F."” porque nos volvemos como burros en busca de nuestra gente y dizque a tratar de arreglarle la situación a los trabajadores. 
Las frecuencias de estos usos, presentados por Travis (2006), son las siguientes: discurso referido: $56 \%$ en el corpus oral y 33\% en el corpus escrito; fuente ajena inespecífica: $37 \%$ en el corpus oral, $37 \%$ en el corpus escrito; labeling: $7 \%$ en el oral y $16 \%$ en el escrito; y la función dubitativa: $0 \%$ en el corpus oral y $6 \%$ en el corpus escrito.

Por otra parte, Miglio (2010), a partir del análisis y la comparación de diferentes corpus orales y escritos -Corpus del español de Mark Davies, Corpus diacrónico del español (CORDE), Corpus del español actual (CREA), Documentos Lingüísticos de la Nueva España (DLNE)—, coincide con Magaña (2005) en que actualmente el uso de dizque es mucho más frecuente en Latinoamérica que en España, especialmente en México, República Dominicana y Colombia. De igual manera, Miglio (2010) se ocupa del origen y la evolución de dizque en relación con sus aspectos semánticos y pragmáticos, entre los cuales se encuentran sus significados como forma verbal, adverbial y evidencial. Con respecto a estos usos, la autora señala la necesidad de diferenciar su significado como estrategia evidencial, por un lado, y como forma de modalidad epistémica, por otro.

En la evolución de esta unidad, la autora muestra su origen como un apócope de la forma personal del verbo decir (dize que > diz que), con referencia a un sujeto concreto o a un referente impersonal (se dice que). Esta interpretación impersonal ya era usada en el siglo XIII, según la autora, para referir hechos que el hablante no había presenciado directamente, por ser parte del pasado lejano, para indicar inferencias o rumores, sin que aparezca en este momento ninguna interpretación de dizque para cuestionar la veracidad del enunciado. La tendencia al mayor uso de la interpretación impersonal de esta unidad, según la autora, condujo a su proceso de gramaticalización gracias a la baja agentividad del sujeto y a la forma apocopada del verbo.

La autora señala cómo este uso se difundió en España hasta el siglo XVI, para el XVII ya se consideraba una unidad informal, provinciana, propia del discurso oral, y en el siglo XVIII su uso disminuyó ostensiblemente. Ya convertido en una colocación, dizque deja de ser una construcción de discurso indirecto para derivar en una estrategia evidencial. De esta manera, con la ausencia de referencia a un sujeto específico, esta unidad asumió los usos de marcador de información de segunda mano, de rumor y de conocimiento compartido, al tiempo que adquiere una interpretación también adverbial y ya no de verbo más complemento, pero diferenciada de los anteriores que son de carácter evidencial. La autora resalta que hasta el siglo XVI no se encuentran ejemplos de significado epistémico de dizque.

Este significado epistémico, según Miglio (2010), es secundario y derivado del significado evidencial, para lo cual se apoya en los argumentos tipológicos de Aikhenvald (2006) y en la evidencia recogida en su análisis diacrónico de los corpus observados. Este significado empieza a aparecer a principios del siglo XVII, al lado del significado que la autora denomina mirative meaning. La adquisición de estos significados es lo que marca realmente el cambio 
significativo en la evolución de esta unidad, junto con el hecho de que haya migrado del registro formal al informal y de la escritura a la oralidad, excepto en los textos literarios modernos y contemporáneos, donde continuó teniendo una presencia significativa, debido a su propósito de reflejar la oralidad.

En otro estudio sobre dizque realizado en México, De la Mora y Maldonado (2015) coinciden con otros estudios realizados en el español mexicano en el hecho de que dizque ha ido perdiendo su significado evidencial para favorecer un uso epistémico, es decir, es una unidad que actualmente se usa más para cuestionar la veracidad de los enunciados que para introducir discurso reportado, aunque reconocen que en otras variedades del español, como en Ecuador (Olbertz, 2005) y Colombia (Travis, 2006), se encuentran todavía usos cuyo significado central es una estrategia evidencial reportativa. Estos autores retoman la descripción de la evolución que ha tenido dizque, en la cual recogen las conclusiones de otros trabajos citados en este artículo (Olbertz, 2005 y 2007; Magaña, 2005; Travis, 2006; Miglio, 2010), en cuanto a que esta unidad ha pasado de usarse como construcción verbal introductora de discurso indirecto, y luego como evidencial de fuente de segunda mano, pasando por el significado de rumor, hasta llegar a usarse como un marcador de modalidad epistémica, junto con otros usos como el de marcación de nombres, adjetivos y sintagmas preposicionales, tal como lo han mostrado Travis (2006) y Miglio (2010).

Si bien De la Mora y Maldonado (2015) aceptan el análisis según el cual el significado de dizque se ha extendido desde su uso de marcador evidencial-reportativo hasta uno en el cual se usa como marcador de modalidad epistémica, sostienen que este análisis es aceptable en términos diacrónicos, aunque parcialmente, pues desde muy temprano en la aparición de esta unidad se encuentran usos no reportativos, no siendo así en el uso contemporáneo, ya que, como lo indican los autores, es difícil encontrar en los estudios hechos en el español de México y Colombia usos en los cuales el significado sea solo reportativo. Según los autores, es mucho más frecuente encontrar realizaciones de dizque en las que se cuestiona la veracidad de los eventos enunciados, incluso sin que se presenten valores reportativos.

De esta manera, los autores concluyen que el significado central de dizque es el cuestionamiento de la veracidad de los eventos referidos. Además de este significado, De la Mora y Maldonado (2015) señalan cómo a partir de él se abre la puerta para la aparición de otros usos pragmáticos, como el denominado uso mirative, y para referirse a acciones falsas. En relación con este último, resulta interesante la descripción que hacen los autores de matices, o una escala de evaluación, para valorar acciones en relación con la descalificación que puede hacer el hablante de los hechos referidos, ya sean insuficientes, levemente falsos o totalmente falsos. Este sentido de descalificación adoptado en el uso de dizque sería el cambio crucial en el significado de esta unidad en el español actual de México, lo cual sirve como argumento para sostener que en el caso de dizque, por lo menos en el español mexicano, la subjetividad, propia de los significados epistémicos y de descalificación, ha desplazado el uso evidencial. 
Es importante resaltar el análisis con el que se concluye el artículo referenciado (De la Mora y Maldonado, 2015), donde los autores muestran que el vacío dejado por dizque para indicar valores evidenciales parece ser llenado por otros marcadores con este significado, como es el caso de Que dizque, en el cual la introducción de que recupera el valor reportativo. Además, aparece el marcador quesque, el cual se encuentra a caballo entre dizque y Que dizque en la expresión de evidencialidad y miratividad.

Teniendo en cuenta los estudios que se han reseñado en este apartado, se plantearon, entonces, las dos hipótesis que guiaron el análisis de dizque en el corpus PRESEEA-Medellín: si se observa esta muestra del habla de Medellín, se encontrarán diferentes funciones para esta unidad (polifuncionalidad); y si se analiza su uso en relación con las variables sociales, se encontrará que estas últimas influirán sobre la frecuencia de uso de cada una de sus funciones.

\section{Metodología}

La investigación de la cual se desprende este artículo se desarrolló dentro del marco del Proyecto de Estudio Sociolingüístico del Español de España y América (PRESEEA), coordinado por el doctor Francisco Moreno Fernández, específicamente dentro del proyecto PRESEEA-Medellín, coordinado por la doctora María Claudia González Rátiva. Para el análisis de los verbos de actitud proposicional, se tomó como referencia el Corpus PRESEEA-Medellín², el cual fue construido teniendo en cuenta los aspectos metodológicos del proyecto internacional (PRESEEA, 2003) y los específicos del Corpus PRESEEA-Medellín (González Rátiva, 2007; Andrade, González y Jaramillo, 2008; González Rátiva y Grajales Alzate, 2011), los cuales determinan la representatividad de la muestra y la estratificación de los informantes. Este corpus está constituido por 72 entrevistas semidirigidas, realizadas a igual número de informantes, de 45 minutos de duración, aproximadamente, cada una, lo cual constituye alrededor de 54 horas de grabación con su respectiva transcripción, con poco más de 840.000 palabras. Los 72 informantes están estratificados de acuerdo con las variables de género, edad, nivel educativo y clase social, distribuidos de manera que se expone en la Tabla 1.

Para obtener la muestra de la estrategia evidencial dizque que se analizaría, se tomaron las transcripciones de las entrevistas y se extrajeron todas sus ocurrencias, en el turno de habla completo en el que se producían, incluyendo la pregunta precedente, para interpretar sus significados dentro del contexto en que se producían.

2 Disponible en el sitio web http://comunicaciones.udea.edu.co/corpuslinguistico/?opcion=0 


\section{TABLA 1}

Número de informantes por cada una de las variables y las categorías

\begin{tabular}{|c|c|c|}
\hline \multicolumn{2}{|c|}{ VARIABLES } & $\begin{array}{l}\text { NÚMERO DE } \\
\text { INFORMANTES }\end{array}$ \\
\hline \multirow{2}{*}{ SEXO } & Hombres & 36 \\
\hline & Mujeres & 36 \\
\hline \multirow{3}{*}{ EDAD } & Generación 1 (20-34 años) & 24 \\
\hline & Generación 2 (35-54 años) & 24 \\
\hline & Generación 3 (55 o más años) & 24 \\
\hline \multirow{3}{*}{ NIVEL EDUCATIVO } & 1 (primaria) & 24 \\
\hline & 2 (secundaria) & 24 \\
\hline & 3 (superior) & 24 \\
\hline \multirow{3}{*}{ CLASE SOCIAL } & Popular & 42 \\
\hline & Media & 23 \\
\hline & Alta & 7 \\
\hline \multicolumn{2}{|c|}{ TOTAL DE INFORMANTES } & 72 \\
\hline
\end{tabular}

En cuanto a la validación de este análisis, se recurrió a la estrategia de evaluación de jueces con la participación de otros tres investigadores. El análisis de coeficiente Kappa de sus respuestas arrojó un índice de 0.75 .

Con respecto al análisis cuantitativo, se partió de la hipótesis general de que el uso de la estrategia evidencial dizque está relacionado con las variables sociales, es decir, que las frecuencias de uso de esta unidad pueden variar de un grupo a otro, lo cual indicaría las tendencias de uso de estas expresiones evidenciales dentro de la comunidad.

Con el fin de comprobar si los datos tenían una distribución normal, se aplicó la prueba de normalidad Kolmogorov-Smirnov. Dado que los resultados mostraron que los datos no provenían de una distribución normal, se utilizaron pruebas no paramétricas para los análisis.

Para cada una de las funciones de dizque analizadas, se plantearon una hipótesis nula $\left(\mathrm{H}_{0}\right)$ y una hipótesis alternativa $\left(\mathrm{H}_{1}\right)$ en relación con cada una de las variables sociales. Por ejemplo, para dizque en relación con la variable de género se formularon así: $\mathrm{H}_{0}$ : No existen diferencias estadísticamente significativas entre hombres y mujeres con respecto al uso de dizque; $\mathrm{H}_{1}$ : Existen diferencias estadísticamente significativas entre hombres y mujeres con respecto al uso de dizque; y así para cada una de las variables sociales.

Para contrastar estas hipótesis en la variable de género para todos los casos analizados, se aplicó la prueba de Mann-Whitney para dos muestras independientes, pues en esta varia- 
ble se contaba con dos categorías. Para todas las otras variables, por tratarse de variables con tres categorías cada una, se aplicó la prueba de Kruskal-Wallis para muestras independientes en todos los casos.

\section{Dizque en el español de Medellín}

En la observación y análisis del corpus se establecieron seis funciones de dizque, las cuales son: la función de modalidad epistémica, la función de indicación de discurso referido sin precisar la fuente, la indicación de discurso directo, la indicación de discurso indirecto, el dizque como marca de elementos nominales, y la indicación del modo de acceso cognitivo a la información.

A continuación, se describen y ejemplifican cada una de estas funciones, teniendo en cuenta los diferentes significados del campo semántico de la evidencialidad, los estudios consultados sobre la unidad dizque y el análisis del comportamiento de esta unidad en cada uno de los contextos que se extrajeron del corpus.

\subsection{Dizque con función de modalidad epistémica}

La primera función es la de modalidad epistémica, que representa el 21\% de la totalidad de las muestras de dizque. En este uso de esta unidad, dizque no significa solo "lo dicho por alguien" o "se dice algo", como han afirmado muchos autores (Travis, 2006; Olbertz, 2007; García Fajardo, 2009) que es su significado de base, sino que también funciona como un marcador que resalta un determinado hecho y cuestiona su certeza, lo califica y lo valora desde una perspectiva subjetiva. Esta función se puede observar en los siguientes ejemplos:

(24) E.: 〈silencio/> ¿qué hace en un día normal / desde que se levanta hasta que se acuesta? I.: pues / mucho rato leer / y otro rato hacer / ayudar aquí en la casa / a los oficios / y otro rato / que yo tengo mucha herramienta todavía / como trabajé en mecánica tantos años / tengo mucha herramienta y hago los arreglitos de la casa / y mucho tiempo m hacía los del vecindario/ / pero ya me dio<alargamiento/> una cosa en los pies / y entonces ya no volví a trabajar / pero yo / como le digo / yo mato el tiempo / yo no / por eso me me extraña con la gente que dice / que se aburre dizque porque que no tienen qué hacer/ / yo a toda hora encuentro qué hacer / quisiera levantarme más temprano para que me rindiera más el día /

(25) I.: esos brujos que adivinan la suerte / yo no sé qué / y entonces dizque consiguen plata / y yo diario los veo lo mismo de pobres /

En los ejemplos anteriores el significado de dizque se puede interpretar como "no me consta y lo pongo en duda". En este sentido, al significado evidencial que indica la fuente indirecta 
de la información se le agrega el significado de modalidad epistémica, en cuanto hace una valoración de la veracidad de la información. De tal manera, dizque es un marcador evidencial que puede expresar simultáneamente la evidencialidad y la modalidad epistémica, aunque en estos casos sobresale la segunda y no es exclusiva la función de marcar la fuente de la información, lo que sí ocurre (como se verá más adelante) en los casos en que dizque solo indica la fuente sin ningún tipo de valoración epistémica.

Esta interpretación está absolutamente ligada al contexto. En el caso de (24) se pone en duda la razón que da la gente cuando afirma que se aburre y el hablante refuerza esta valoración epistémica indicando su extrañeza y aportando un argumento contrario. De igual manera, en (25) el hablante cuestiona la afirmación, no se sabe bien si de los brujos o de otras personas, a quienes se les atribuye el contenido, aportando un argumento opuesto.

En los casos de dizque con esta función, en la cual además del significado "Io pongo en duda" también está operando el significado "no me consta", esta unidad afecta cláusulas completas, al igual que otras funciones en las que se privilegia la indicación de la fuente de información. Esta indicación está estrechamente relacionada con la modalidad epistémica en las lenguas en las que se marca de manera léxica la evidencialidad. El hecho de que un hablante dé a entender explícitamente con dizque que la información que presenta es de segunda mano implica que no es él quien es responsable de la veracidad de los hechos que describe, pero no automáticamente que el hablante no se fíe de la veracidad de estos hechos, lo cual depende - tanto que haya o no tal implicación-completamente del contexto.

\subsection{Dizque como indicador de fuente ajena imprecisa}

La segunda función, que representa el 26\% de las ocurrencias de dizque en el corpus, es la indicación de la fuente de la información como ajena, sin especificar la fuente misma. Algunos autores han denominado a esta función como hearsay (Travis, 2006) o como indicador de que la fuente es ajena al hablante. En el caso de nuestro corpus, es necesario separar esta función de otras que también marcan la información como proveniente de una fuente ajena, como es el caso de la función anterior con indicación de modalidad epistémica y la introducción de discurso directo e indirecto. Esta función indica que la fuente de la información presentada es externa al hablante, no personal, y esa fuente es inespecífica, por lo cual se puede interpretar como "se dice" o "la gente dice”, sin que nada en el contexto indique que se está cuestionando la veracidad de la información. Esto se puede observar en los siguientes ejemplos:

(26) E: ¿le gusta vivir en Medellín?

I: joh! claro

E: y por qué

I: la gente es muy bacana/ esto aquí pues es muy bonito y tenemos muchas partes para 
donde irnos a Medellín/ para donde mirar pues para donde coger/ si vamos para el sur/ para el norte / el clima por lo que estábamos hablando ahorita espectacular pues/ a comparación de otras ciudades dizque Medellín es clima fabuloso y/ agradable vivir acá

(27) no y a mí me da mucha pereza comer bastante pa acostarme / más bien me acuesto / me acuesto / como poquitico / si como / como a las cinco / sí / la comida es aquí a las seis de la tarde pa todos / para que se acuesten ya que haigan andado / no se les / no ve que una vez dizque se acostó una señora que se comió media gallina / como pa no dejar para el otro día y se murió / y se le torcieron las tripas y le dio peritonitis / no pues / es que / como es que dice la / la gula con la abstinencia / la tibieza con el fervor / todas mis inclinaciones y afectos carnales / vuestro santo temor y amor de Dios / es hasta pecado comer de gula /

En estos ejemplos dizque está indicando que la afirmación que el hablante aporta no la obtuvo de manera personal, sino a través de una fuente ajena, pero no especifica la fuente, por lo cual también se puede interpretar la información como de acceso compartido por muchos, por lo tanto, podría interpretarse en ambos casos como "dicen que”. Cuando dizque cumple esta función no se activa la interpretación de "lo pongo en duda”, a no ser que explícitamente se ponga en duda la información en el contexto lingüístico, por lo cual se diferencia de la función de modalidad epistémica.

Al igual que para el caso de la función de modalidad epistémica, aquí la interpretación de la ausencia de una implicación de valoración de la veracidad o fiabilidad del contenido es contextual. En el ejemplo (26) dizque introduce una afirmación indicando que es de una fuente ajena sin especificarla, pues no se le atribuye a una persona o a un grupo en específico, pero no se puede interpretar como "lo pongo en duda", ya que el contenido introducido va en la misma dirección argumentativa del hablante y corrobora lo que acaba de decir, por lo cual se interpreta que asume como válida la información. En el ejemplo (27) ocurre algo similar. En este caso, para la información que se atribuye a una fuente ajena, está claro que no se pone en duda, porque en el contexto se asume el contenido presentado como un hecho acontecido y se insertan sus consecuencias en la argumentación del hablante sin cuestionar su veracidad.

Con esta función, dizque también afecta cláusulas completas. Obviamente, como se ha señalado antes, el hecho de que se presente la información como de segunda mano implica que el hablante se distancie de la responsabilidad de la veracidad de la información presentada, pero como se puede ver, y como se resaltó anteriormente, la valoración de la fiabilidad o no del contenido proposicional depende del contexto. Para el caso de esta función de dizque, de acuerdo con los contextos en que se realiza, no se pone en duda el contenido que se presenta.

\subsection{Dizque introductor de discurso directo}

Otra de las funciones de dizque que se encuentra en el corpus es la introducción de discurso directo, que constituye el $21 \%$ del total de las ocurrencias de esta unidad. Esta función indica 
claramente que la información es de segunda mano y clarifica la fuente de la información, atribuyéndola a una persona o a un grupo de personas. Esto se puede observar en los ejemplos que se presentan a continuación:

(28) una vez que veníamos del centro cuando el niño / él tenía en ese tiempo cuatro o cinco años / veníamos ya ahí en la estación de San Antonio y yo me confié de que el niño pues lo traía pues el papá / y en ese momento llegó el Metro que iba hacia Itagüí / hubo un momento en el que / cuando ya toda la gente se fue me dio por mirar a mi esposo y yo no lo vi con el niño / y yo miraba para todas partes y yo ¿y el niño? y yo Néstor / el niño dizque cómo así / ¿usted no lo traía? y yo no / usted lo traía / dizque no / el niño jay Dios mío! / me pongo yo a llorar / yo era ya desesperada / unos policías entonces me vieron señora qué le pasó / y yo mi niño se me perdió dizque cómo así / y cuántos años tenía/ con qué ropa estaba vestido / y yo él llevaba un buzo amarillo / un pantalón café / entonces ya empezaron pues los policías de una a reportarse en el Metro

(29) entonces llegamos como decir / Junín con San Juan / yo bueno / maestro / hasta aquí porque yo voy para La América / me dijo / no / yo voy como para Manrique / y le dije / no / es que yo por allá no paso hermano / dizque me tiene que llevar / le dije / no viejo yo no lo tengo que llevar / yo con mucho gusto hasta aquí lo traje pero yo no voy para allá /

En estos ejemplos se puede observar claramente que dizque introduce enunciados atribuidos a una fuente ajena y se especifica quién proporcionó la información que se está transmitiendo, conservando la perspectiva y la deixis del acto de habla que se está refiriendo, lo cual activa una interpretación más literal del contenido que se está transmitiendo, además como parte de un evento en el que el hablante participó, y de ninguna manera activa la interpretación de poner en duda la información presentada como de segunda mano.

El hecho de que dizque introduzca discurso directo muestra su independencia actual del significado de las formas de las cuales se derivó como unidad (dice que, dicen que), relacionadas con la introducción de discurso indirecto. Es importante también señalar que, para introducir el estilo directo, dizque no necesita ir acompañado de un verbo de comunicación, tal como se evidencia en los ejemplos anteriores.

\subsection{Dizque introductor de discurso indirecto}

Dizque también introduce discurso indirecto, función que representa el 10\% del total de ocurrencias de esta unidad en el corpus. Como es obvio, en la introducción de discurso indirecto también se indica que la información es de segunda mano y se le atribuye a una persona o a un grupo de personas específicas. Esta función se ejemplifica a continuación: 
(30) yo / iba / fui a llevar una persona por allá a un barrio que yo no conocía / extremo / y en/ al regreso me / un tipo me pone la mano / el <ininteligible/> era personal / dizque lo bajara hasta el centro de la ciudad / entonces yo lo bajé/

(31) yo ese día estaba como / como muy / pues / enlagunado / pero yo como que / de ese / en e / a mí se me quitó como ese día esa rasca / yo no sé / y entonces / mhm / yo / yo sentí que / yo sentí la muerte ahí en ese momento / de varios atentados que me habían hecho / me vine para la casa / yo no sé si amane<palabra_cortada/> al otro día me / amanecí aquí y mis hermanas me dijeron dizque me habían traído yo no sé cómo /

En estos casos, dizque introduce enunciados atribuidos a una persona específica o a un grupo de personas, desde la perspectiva del acto de habla actual y no desde la del acto de habla referido, es decir, se reproducen las palabras desde el sistema de referencias deícticas del hablante que reproduce el discurso, y en la mayoría de los casos no se puede interpretar que se ponga en duda la información, a pesar del distanciamiento que implica presentar la información de manera indirecta.

En el ejemplo (31), la presencia de la construcción yo no sé cómo activa una interpretación epistémica sobre la falta de certidumbre respecto a la manera en que "habían traído" al informante. No obstante, se clasifica como una función de discurso indirecto de dizque porque introduce un enunciado atribuido a un grupo de personas concreto, característica que no aparece en la función de modalidad epistémica, en la cual, además de ser inespecífica la fuente, en el contexto lingüístico se indica el cuestionamiento de la veracidad del enunciado. De esta manera, la clasificación que se propone en este análisis distingue, por un lado, los usos epistémicos sin información reportativa y, por el otro, los usos reportativos, aunque estos últimos pudieran interpretarse en algunos casos como epistémicos.

Al igual que en el caso de dizque como introductor de discurso directo, en la introducción de discurso indirecto también puede aparecer sin estar acompañado de un verbo de comunicación, como se observa en (30), y también aparece acompañado de verbo de comunicación, como en el ejemplo (31).

\subsection{Dizque marcador de elementos nominales}

En el corpus analizado también se encontró una función de dizque que aquí se ha denominado como marcación de elementos nominales, que aparece con el 17\% del total de las ocurrencias de dizque analizadas. Otros investigadores (Travis, 2006; Olbertz, 2007) han reportado esta función de dizque en el sentido de que puede aparecer afectando no cláusulas completas (como en los casos vistos aquí de modalidad epistémica, fuente ajena y discurso directo e indirecto), sino constituyentes de la oración (Olbertz, 2007) o sintagmas (Travis, 2006), ya sean nominales o preposicionales. En los casos registrados en el corpus, esta unidad afecta 
elementos nominales y en todos los casos se trata de nombres propios. Esta función se diferencia de las anteriores, tanto de la introducción de estilo directo e indirecto como de la indicación de la fuente de la información ajena e imprecisa, así como de la modalidad epistémica, en cuanto a su alcance, pues esta función aparece en un contexto formal distinto a los anteriores, introduciendo nombres propios. A continuación, se muestran los ejemplos:

(32) tenemos todos los parques de los barrios/ excelente / unos parques divinos / está el planetario / que es un / tenemos lo que es los parques de comunales / que son las unidades deportivas / tenemos por decir / la unidad de allí dizque Juanes / ahí por la sesenta y cinco / por toda la autopista

(33) jugábamos escondidijo / bate aquí en/ en esta zona verde que hay al lado de la placa deportiva/ mhm jugábamos por toda la cuadra dizque Yeimi/ de todo/ hacíamos de todo/ seguimiento/ eso era/ lo mejor/ yo creo que la niñez es lo mejor

(34) jah! esa fue lo una de las que más me / una borrachera de esas ihm! / yo trabajaba en / en una cosa dizque Nacional de Construcciones / por allá en el centro recuerdo /

(35) hace mucho tiempo / yo estaba en / en otro colegio / no en el que me gradué sino en otro / dizque el San Vicente de Paúl / me metí por allá por López de Mesa y me robaron un bolso /

En estos ejemplos dizque solo indica que el elemento marcado no es atribuible al informante. En ninguno de los casos se pone en duda la información. De hecho, como se puede apreciar en los ejemplos, el hablante hace referencia a un elemento que conoce dentro de un evento en el que él participa. Se podría afirmar que en los ejemplos anteriores el informante presenta la información introducida por dizque como nueva para su interlocutor, aunque de hecho no lo sea, y le indica que la información no es de acceso privativo, sino compartido, por lo cual podría interpretarse como "llamada" en (32) y (34), "eso que llaman” o "eso llamado" en (33), y "Ilamado" en (35). En el dizque denominado de fuente ajena e imprecisa el hablante enfatiza el carácter ajeno de la fuente de información, mientras que el dizque de marcación de elementos nominales resalta la condición de compartida de la información. Esto último (marcar si la información es compartida o privativa) es un eje dentro de los cuales se ubican los significados que codifican los evidenciales, de acuerdo con la propuesta de Bermúdez (2006), por lo cual se puede describir como una función independiente de dizque.

No obstante, si bien esta función no especifica la fuente de la información, sí indica que el elemento introducido no es atribuible al hablante exclusivamente y esto la acerca a la de modalidad epistémica y a la de fuente inespecífica. De hecho, la función de marcación de elementos nominales y la de fuente ajena e inespecífica comparten la característica de que el hablante presenta la fuente de la información como genérica o de alcance universal: "se dice" o "la gente dice”, en el caso de la fuente ajena; "Ilamado" por todo el mundo o "eso que llaman" todos, en el caso de la marcación de elementos nominales. Sin embargo, la separación de estas dos funciones se justifica porque se diferencian en el alcance (la primera afecta 
cláusulas, mientras que la segunda solo elementos nominales) y en su interpretación, pues entre las dos hay una diferencia de énfasis: la función de fuente ajena e inespecífica enfatiza que la fuente no es propia, mientras que la función de marcación de elementos nominales acentúa que la información es compartida por todos, incluido el hablante. En este sentido, la función de marcación implica siempre que la interpretación de la fuente es universal, es decir, compartida, mientras que la función de fuente ajena inespecífica no necesariamente implica esto, como en el caso de (27) —alguien le contó algo al hablante, pero no todo el mundo-, donde queda claro que la fuente es ajena, pero de ninguna manera que la información sea compartida por todos los hablantes de manera genérica.

\subsection{Dizque indicador de modo de acceso cognitivo}

Otra de las funciones encontradas para dizque en el corpus es la indicación del modo de acceso cognitivo a la información, que representa el 5\% del total de las ocurrencias de esta unidad. Esta función se encuentra dentro de lo que Bermúdez (2006) denominó el primer eje de los significados que codifican los evidenciales, que corresponde al continuo entre lo sensorial y lo cognitivo. Este respondería a la pregunta ¿cómo se obtuvo la información? Dentro de este eje, en el polo cognitivo, Bermúdez incluye los evidenciales que indican que la información que se está transmitiendo es una suposición, una fantasía (como en el juego de los niños) o un sueño. En español existen algunos usos del pretérito imperfecto que cumplen esta función (Bermúdez, 2006). En el corpus analizado se encontraron casos de dizque en los que aparece en relatos de sueños, acompañando al pretérito imperfecto, reforzando la interpretación de la información como un proceso cognitivo. Esto se puede apreciar en los siguientes ejemplos:

(36) E.: ¿ha tenido algún sueño que lo haya impresionado?

I.: sí / un sueño que tuve yo que me impresionó mucho / fue un sueño con unas culebras / yo estaba como enfermo / como con fiebre / y eso así / y debido a la fiebre / entonces yo veía como culebras que me iban a morder / y yo me le tiraba dizque a mi mamá/ y en fin / y culebras / y como unos animales ahí / lo que más me ha impresionado pues en la vida E.: y picado

I.: no / yo no dizque me dejaba / entonces ellos me iban a picar y yo les mandaba el manotón / y entonces no / no me picaban / y yo corría dizque a esconderme detrás de mi mamá / pero no valía / eso era como soñando / como un / debido a la fiebre creo yo que era

(37) tuve un sueño que yo nunca he podido saber eso qué quería decir porque soñé que / dizque estaba con Dios y que me dijo que si yo quería que si él que<palabra_cortada/> que si yo quería que él me abriera el tercer ojo /

En los ejemplos anteriores se puede ver que dizque está reforzando la indicación del origen de la información como de carácter cognitivo, en este caso en particular como parte de un 
sueño, acompañando el pretérito imperfecto que, según Bermúdez (2006), es la forma gramaticalizada en español para indicar este tipo de evidencia. En este caso es claro que dizque no presenta ningún valor reportativo.

Las funciones de dizque descritas en este apartado se encuentran distribuidas en el corpus, ordenadas de acuerdo con su frecuencia, como puede observarse en la Tabla 2.

TABLA 2
Frecuencia de las funciones de dizque
\begin{tabular}{lcc}
\hline FUNCIÓN & N & $\%$ \\
\hline Fuente ajena imprecisa & 40 & $26 \%$ \\
\hline Modalidad epistémica & 33 & $21 \%$ \\
\hline Discurso directo & 33 & $21 \%$ \\
\hline Marca de elementos nominales & 27 & $17 \%$ \\
\hline Discurso indirecto & 15 & $10 \%$ \\
\hline Modo de acceso cognitivo & 7 & $5 \%$ \\
\hline Total & 155 & $100 \%$ \\
\hline
\end{tabular}

Como se puede ver en estos datos, la función de dizque más frecuente en el español de Medellín es la de Fuente ajena imprecisa (26\%), seguida de la función de Modalidad epistémica (21\%), introducción de discurso directo (21\%), Marca de elementos nominales (17\%), y las menos frecuentes son la introducción de discurso indirecto (10\%) y la de Modo de acceso cognitivo (5\%).

\section{Dizque en relación con las variables sociales}

En este análisis se buscó verificar si existían diferencias estadísticamente significativas en el uso de dizque en relación con las variables de género, generación, nivel educativo y clase social. Dado que la muestra no tiene una distribución normal, se aplicaron pruebas no paramétricas para verificar las hipótesis. En un principio se presentarán los estadísticos descriptivos de las funciones de dizque en el corpus analizado, y luego se presentará, para cada una de las variables, si existen o no diferencias estadísticamente significativas. Es importante anotar que, además de los datos de significancia (cuando haya lugar a ellos), se presentarán los rangos de cada una de las funciones, pues se verá que en algunos casos, aunque no haya diferencias estadísticamente significativas, las tendencias de los rangos dan información cualitativa que es valiosa para posteriores interpretaciones. 
En cuanto a los estadísticos descriptivos, se obtuvo la información apreciable en la Tabla 3.

\section{TABLA 3}

Frecuencia de las funciones de dizque

\begin{tabular}{lcc} 
& MEDIA & DESVIACIÓN \\
Modalidad epistémica & .46 & .963 \\
\hline Fuente ajena imprecisa & .56 & .948 \\
\hline Discurso directo & .46 & 1.162 \\
\hline Discurso indirecto & .21 & .473 \\
\hline Marcación de elementos nominales & .38 & 1.204 \\
\hline Modo de acceso cognitivo & .10 & .508 \\
\hline Total & 2.15 & 2.996
\end{tabular}

Al analizar el uso de dizque en relación con las variables sociales, se encontró que existen diferencias estadísticamente significativas con respecto a la variable de género ( $\mathrm{N}=$ número de informantes), como se aprecia en las Tablas 4 y 5.

\section{TABLA 4}

Resultados dizque variable género

\begin{tabular}{lllc} 
& GÉNERO & N & $\begin{array}{c}\text { RANGO } \\
\text { PROMEDIO }\end{array}$ \\
\multirow{2}{*}{$\begin{array}{l}\text { Total } \\
\text { Dizque }\end{array}$} & Hombre & 36 & 41.53 \\
\cline { 2 - 4 } & Mujer & 36 & 31.47 \\
\cline { 2 - 4 } & Total & 72 & \\
\hline
\end{tabular}

\section{TABLA 5}

Resultados de contraste dizque variable género

\begin{tabular}{cc} 
& $\begin{array}{c}\text { TOTAL } \\
\text { DIZQUE }\end{array}$ \\
\hline U de Mann-Whitney & 467.000 \\
\hline W de Wilcoxon & 1133.000 \\
\hline$Z$ & -2.132 \\
\hline Sig. asintót. (bilateral) & .033 \\
\hline
\end{tabular}

Aquí se puede observar que los hombres usan más que las mujeres la unidad dizque y esta diferencia es significativa (Sig.= .033). Al analizar los rangos de cada una de las funciones descritas, se obtuvo la información presentada en las Tablas 6 y 7. 


\section{TABLA 6}

Resultados funciones de dizque variable género

\begin{tabular}{|c|c|c|c|}
\hline & GÉNERO & $\mathbf{N}$ & $\begin{array}{c}\text { RANGO } \\
\text { PROMEDIO }\end{array}$ \\
\hline \multirow{3}{*}{$\begin{array}{l}\text { Modalidad } \\
\text { epistémica }\end{array}$} & Hombre & 36 & 41.69 \\
\hline & Mujer & 36 & 31.31 \\
\hline & Total & 72 & \\
\hline \multirow{3}{*}{$\begin{array}{l}\text { Fuente ajena } \\
\text { imprecisa }\end{array}$} & Hombre & 36 & 38.79 \\
\hline & Mujer & 36 & 34.21 \\
\hline & Total & 72 & \\
\hline \multirow{3}{*}{ Discurso directo } & Hombre & 36 & 35.43 \\
\hline & Mujer & 36 & 37.57 \\
\hline & Total & 72 & \\
\hline \multirow{3}{*}{ Discurso indirecto } & Hombre & 36 & 39.90 \\
\hline & Mujer & 36 & 33.10 \\
\hline & Total & 72 & \\
\hline \multirow{3}{*}{$\begin{array}{l}\text { Marcación de } \\
\text { elementos nominales }\end{array}$} & Hombre & 36 & 41.93 \\
\hline & Mujer & 36 & 31.07 \\
\hline & Total & 72 & \\
\hline \multirow{3}{*}{$\begin{array}{l}\text { Modo de acceso } \\
\text { cognitivo }\end{array}$} & Hombre & 36 & 36.99 \\
\hline & Mujer & 36 & 36.01 \\
\hline & Total & 72 & \\
\hline
\end{tabular}

\section{TABLA 7}

Resultados contraste funciones de dizque variable género

\begin{tabular}{lcccccc} 
& $\begin{array}{c}\text { MODALIDAD } \\
\text { EPISTÉMICA }\end{array}$ & $\begin{array}{c}\text { FUENTE } \\
\text { AJENA } \\
\text { IMPRECISA }\end{array}$ & $\begin{array}{c}\text { DISCURSO } \\
\text { DIRECTO }\end{array}$ & $\begin{array}{c}\text { DISCURSO } \\
\text { INDIRECTO }\end{array}$ & $\begin{array}{c}\text { MARCACIÓN } \\
\text { DE ELEMENTOS } \\
\text { NOMINALES }\end{array}$ & $\begin{array}{c}\text { MODO DE } \\
\text { ACCESO } \\
\text { COGNITIVO }\end{array}$ \\
\hline U de Mann-Whitney & 461.000 & 565.500 & 609.500 & 525.500 & 452.500 & 630.500 \\
\hline W de Wilcoxon & 1127.000 & 1231.500 & 1275.500 & 1191.500 & 1118.500 & 1296.500 \\
\hline Z & -2.775 & -1.115 & -.628 & -2.065 & -3.287 & -.569 \\
\hline Sig. asintót. (bilateral) & .006 & .265 & .530 & .039 & .001 & .569 \\
\hline
\end{tabular}

De acuerdo con estos datos, se puede apreciar que, excepto en la función de introducción de discurso directo, las mujeres tienden a usar menos que los hombres las diferentes funciones de dizque. Sin embargo, no en todas las funciones existen diferencias estadísticamente signi- 
ficativas; estas diferencias significativas se dan en la modalidad epistémica (Sig.= .006), en la indicación de discurso indirecto (Sig.= .039) y en la marcación de elementos nominales (Sig.=.001).

En cuanto a la variable de clase social, no se encontraron diferencias estadísticamente significativas con respecto al uso de dizque. Sin embargo, si se observan los rangos para cada una de las funciones en relación con la clase social, aparecen unos datos interesantes, como los apreciables en la Tabla 8.

\section{TABLA 8}

Resultados funciones de dizque variable clase social

\begin{tabular}{|c|c|c|c|}
\hline & CLASE SOCIAL & $\mathbf{N}$ & RANGO PROMEDIO \\
\hline \multirow{4}{*}{$\begin{array}{l}\text { Modalidad } \\
\text { epistémica }\end{array}$} & Baja & 42 & 37.18 \\
\hline & Media & 23 & 36.63 \\
\hline & Alta & 7 & 32.00 \\
\hline & Total & 72 & \\
\hline \multirow{4}{*}{$\begin{array}{l}\text { Fuente ajena } \\
\text { imprecisa }\end{array}$} & Baja & 42 & 36.68 \\
\hline & Media & 23 & 38.46 \\
\hline & Alta & 7 & 29.00 \\
\hline & Total & 72 & \\
\hline \multirow{4}{*}{ Discurso directo } & Baja & 42 & 37.89 \\
\hline & Media & 23 & 36.09 \\
\hline & Alta & 7 & 29.50 \\
\hline & Total & 72 & \\
\hline \multirow{4}{*}{ Discurso indirecto } & Baja & 42 & 36.14 \\
\hline & Media & 23 & 39.13 \\
\hline & Alta & 7 & 30.00 \\
\hline & Total & 72 & \\
\hline \multirow{4}{*}{$\begin{array}{l}\text { Marcación de } \\
\text { elementos nominales }\end{array}$} & Baja & 42 & 37.02 \\
\hline & Media & 23 & 37.52 \\
\hline & Alta & 7 & 30.00 \\
\hline & Total & 72 & \\
\hline \multirow{4}{*}{$\begin{array}{l}\text { Modo de acceso } \\
\text { cognitivo }\end{array}$} & Baja & 42 & 36.70 \\
\hline & Media & 23 & 36.59 \\
\hline & Alta & 7 & 35.00 \\
\hline & Total & 72 & \\
\hline \multirow{4}{*}{ Total Dizque } & Baja & 42 & 37.70 \\
\hline & Media & 23 & 38.76 \\
\hline & Alta & 7 & 21.86 \\
\hline & Total & 72 & \\
\hline
\end{tabular}


En estos resultados se puede observar que, tanto para el uso de dizque en general (Total Dizque) como para cada una de sus funciones, la clase social alta tiende a usar menos esta unidad que las otras clases sociales, mientras que para los informantes de las clases sociales media y baja no hay una tendencia tan clara.

En lo concerniente a la variable de generación, no se encontraron diferencias estadísticamente significativas en cuanto al uso de dizque, ni para el uso de esta unidad en general ni para el uso de cada una de sus funciones. Al observar los rangos de las funciones tampoco se vio una tendencia clara, a diferencia de lo que aparece en la variable de clase social, y las diferencias de rangos no permiten observaciones relevantes, como se puede ver en la Tabla 9.

\section{TABLA 9}

Resultados funciones de dizque variable generación

\begin{tabular}{|c|c|c|c|}
\hline & GENERACIÓN & $\mathbf{N}$ & RANGO PROMEDIO \\
\hline \multirow{4}{*}{$\begin{array}{l}\text { Modalidad } \\
\text { epistémica }\end{array}$} & $20-34$ & 24 & 39.33 \\
\hline & $35-54$ & 24 & 34.04 \\
\hline & $55^{-}$ & 24 & 36.13 \\
\hline & Total & 72 & \\
\hline \multirow{4}{*}{$\begin{array}{l}\text { Fuente ajena } \\
\text { imprecisa }\end{array}$} & $20-34$ & 24 & 34.58 \\
\hline & $35-54$ & 24 & 36.98 \\
\hline & $55^{-}$ & 24 & 37.94 \\
\hline & Total & 72 & \\
\hline \multirow{4}{*}{ Discurso directo } & $20-34$ & 24 & 37.15 \\
\hline & $35-54$ & 24 & 35.73 \\
\hline & $55^{-}$ & 24 & 36.63 \\
\hline & Total & 72 & \\
\hline \multirow{4}{*}{ Discurso indirecto } & $20-34$ & 24 & 34.65 \\
\hline & $35-54$ & 24 & 38.75 \\
\hline & $55^{-}$ & 24 & 36.10 \\
\hline & Total & 72 & \\
\hline \multirow{4}{*}{$\begin{array}{l}\text { Marcación de } \\
\text { elementos nominales }\end{array}$} & $20-34$ & 24 & 36.06 \\
\hline & $35-54$ & 24 & 37.48 \\
\hline & $55^{-}$ & 24 & 35.96 \\
\hline & Total & 72 & \\
\hline \multirow{4}{*}{$\begin{array}{l}\text { Modo de acceso } \\
\text { cognitivo }\end{array}$} & $20-34$ & 24 & 36.46 \\
\hline & $35-54$ & 24 & 36.52 \\
\hline & $55^{-}$ & 24 & 36.52 \\
\hline & Total & 72 & \\
\hline
\end{tabular}


Si se miran los datos para el uso de dizque en general, no discriminado por funciones, se obtiene la información presentada en la Tabla 10.

\section{TABLA 10}

Resultados dizque variable generación

\begin{tabular}{lllc} 
& GENERACIÓN & $\mathbf{N}$ & \multicolumn{1}{c}{$\begin{array}{c}\text { RANGO } \\
\text { PROMEDIO }\end{array}$} \\
\cline { 2 - 4 } $\begin{array}{l}\text { Total } \\
\text { Dizque }\end{array}$ & $20-34$ & 24 & 37.46 \\
\cline { 2 - 4 } & $35-54$ & 24 & 34.67 \\
\cline { 2 - 4 } & $55^{-}$ & 24 & 37.38 \\
\cline { 2 - 4 } & Total & 72 & \\
\hline
\end{tabular}

Aquí se puede apreciar que los informantes de la generación 2 (35-54) tienden a usar menos dizque en comparación con las otras dos generaciones, entre las cuales no hay ninguna diferencia en el uso de esta unidad, pero, como ya se dijo, esta diferencia no es significativa.

En relación con los datos de la variable de nivel educativo, tampoco se encontraron diferencias estadísticamente significativas en relación con las funciones de dizque, y en los rangos de cada una de ellas no se aprecian tendencias relevantes, como puede verse en la Tabla 11.

Por otro lado, si se relaciona la variable de nivel educativo con el uso de dizque en general, sin discriminar sus funciones, se obtiene la información presentada en la Tabla 12.

Aquí se puede observar que los informantes que tienen educación superior usan menos dizque en comparación con los otros dos niveles educativos, entre los cuales no se aprecia ninguna diferencia en el uso de esta unidad. Sin embargo, como ya se dijo, esta diferencia no apareció como estadísticamente significativa en el análisis.

Si se toman estos resultados en general, principalmente los concernientes al cruce del uso de dizque como evidencial (Total Dizque) con las diferentes variables sociales, sin discriminar sus funciones, y a pesar de que solo para la variable de género se encontraron diferencias estadísticamente significativas, se puede establecer una tendencia de uso: Ios informantes de género femenino, de clase social alta, de la generación 2 y con nivel educativo superior tienden a usar menos esta unidad.

\section{Discusión}

A partir de la descripción y los resultados presentados en los apartados anteriores, se pueden establecer algunas observaciones particulares y generales sobre el comportamiento de diz- 


\section{TABLA 11}

Resultados funciones de dizque variable nivel educativo

\begin{tabular}{|c|c|c|c|}
\hline & NIVEL EDUCATIVO & $\mathbf{N}$ & RANGO PROMEDIO \\
\hline \multirow{4}{*}{$\begin{array}{l}\text { Modalidad } \\
\text { epistémica }\end{array}$} & Primaria & 24 & 38.19 \\
\hline & Secundaria & 24 & 38.27 \\
\hline & Superior & 24 & 33.04 \\
\hline & Total & 72 & \\
\hline \multirow{4}{*}{$\begin{array}{l}\text { Fuente ajena } \\
\text { imprecisa }\end{array}$} & Primaria & 24 & 38.71 \\
\hline & Secundaria & 24 & 36.79 \\
\hline & Superior & 24 & 34.00 \\
\hline & Total & 72 & \\
\hline \multirow{4}{*}{ Discurso directo } & Primaria & 24 & 38.13 \\
\hline & Secundaria & 24 & 35.56 \\
\hline & Superior & 24 & 35.81 \\
\hline & Total & 72 & \\
\hline \multirow{4}{*}{ Discurso indirecto } & Primaria & 24 & 37.83 \\
\hline & Secundaria & 24 & 34.38 \\
\hline & Superior & 24 & 37.29 \\
\hline & Total & 72 & \\
\hline \multirow{4}{*}{$\begin{array}{l}\text { Marcación de } \\
\text { elementos nominales }\end{array}$} & Primaria & 24 & 35.96 \\
\hline & Secundaria & 24 & 39.42 \\
\hline & Superior & 24 & 34.13 \\
\hline & Total & 72 & \\
\hline \multirow{4}{*}{$\begin{array}{l}\text { Modo de acceso } \\
\text { cognitivo }\end{array}$} & Primaria & 24 & 37.98 \\
\hline & Secundaria & 24 & 36.52 \\
\hline & Superior & 24 & 35.00 \\
\hline & Total & 72 & \\
\hline
\end{tabular}

\section{TABLA 12}

Resultados dizque variable nivel educativo

\begin{tabular}{llll} 
& \multicolumn{1}{c}{$\begin{array}{c}\text { NIVEL } \\
\text { EDUCATIVO }\end{array}$} & N & \multicolumn{1}{c}{$\begin{array}{c}\text { RANGO } \\
\text { PROMEDIO }\end{array}$} \\
\cline { 2 - 4 } Total & Primaria & 24 & 39.58 \\
\cline { 2 - 4 } Dizque & Secundaria & 24 & 39.23 \\
\cline { 2 - 4 } & Superior & 24 & 30.69 \\
\cline { 2 - 4 } & Total & 72 & \\
\hline
\end{tabular}


que en el español de Medellín, en contraste con otros datos suministrados por otros estudios realizados sobre esta unidad y algunas consideraciones sociolingüísticas.

En primer lugar, con respecto a los datos aportados por Magaña (2005), Olbertz (2007), García Fajardo (2009) y De la Mora y Maldonado (2015) en sus estudios sobre dizque en el español mexicano, se pueden apreciar algunas diferencias. Para estos autores, en el español mexicano el uso de dizque se da principalmente como marcador pragmático evidencial que indica la falta de certeza en una aseveración, es decir, se usa principalmente como marcador de modalidad epistémica. En el español de Medellín esta unidad también presenta este valor, pero no es el único ni el principal. Aunque está entre los usos más recurrentes no es el más frecuente (21\% frente al $26 \%$ de la función que indica la fuente de la información como ajena e imprecisa). En el español de Medellín el uso de dizque con valor de modalidad epistémica aparece al mismo tiempo que otros usos, aunque estos últimos podrían asumir interpretaciones epistémicas en algunos contextos, teniendo en cuenta que en español la información de fuente indirecta está relacionada con la modalidad epistémica, tal como lo muestra Travis (2006) en su trabajo.

Sin embargo, también hay coincidencias entre este trabajo y los estudios citados sobre el español mexicano, en el sentido de que dizque sigue conservando su significado evidencial al marcar la información transmitida como de segunda mano, o "no me consta", y dependiendo del contexto puede o no indicar la falta de certeza, o "lo pongo en duda”, por lo cual se puede sostener que su significado base es evidencial y no de modalidad epistémica.

En segundo lugar, en relación con el estudio de Olbertz (2005) sobre el uso de dizque en el español ecuatoriano en un contexto bilingüe en contacto con el quechua, también se pueden hacer algunos contrastes. Entre las conclusiones principales de aquel estudio se encuentra una que afirma que en aquella variedad del español se ha conservado el uso reportativo o evidencial de dizque con el valor de marcador de discurso directo y no se reportan otros usos. En la descripción que se hizo más arriba sobre dizque en el español de Medellín, se evidencia que también tiene el valor descrito por Olbertz (2007) y, aunque se encuentra entre los usos más frecuentes, no es el único uso que se le da, como ha quedado expuesto en la descripción. Además, Olbertz (2005 y 2007) resalta que en el español ecuatoriano dizque como marcador de discurso directo siempre aparece acompañado del verbo decir, mientras que en el español de Medellín dizque, cuando cumple esta función, aparece sin ir acompañado del verbo decir en todos los casos.

En tercer lugar, específicamente sobre el uso de dizque en el español colombiano, se encuentra el estudio realizado por Travis (2006), con respecto al cual se encuentran más coincidencias, pero también divergencias. En el estudio de Travis se reportan cuatro usos de dizque que coinciden en términos generales con los descritos en este trabajo: el primero es el de introducción de discurso referido (reported speech), que en esta descripción se ha desglosado 
en introducción de discurso directo e indirecto; el segundo es el valor de "rumor" (hearsay), que aquí también se ha descrito como fuente ajena imprecisa; el tercero es el uso denominado por la autora como "etiquetado" (labeling), que también se encuentra en nuestro corpus y se describió como marcador de elementos nominales; y el cuarto es el "dubitativo" (dubitative), que solo aparece en el corpus escrito que analizó la autora y que no coincide con la función que denominamos modalidad epistémica, pues como para la autora este significado es contextual no lo aísla como categoría, ya que puede activarse con cualquiera de las funciones. Para Travis (2006) la función dubitativa solo se aplica para los casos en los que dizque introduce una acción o un evento en el que estuvo presente el hablante.

Además de estos contrastes, de acuerdo con Travis (2006), también se ve que las funciones de discurso referido y la de hearsay están entre las más frecuentes en el español colombiano. En el estudio de Travis (2006), en el corpus oral, dizque como introductor de discurso referido alcanza el 56\% de las muestras y dizque de rumor el 37\%. En nuestro corpus dizque como introductor de discurso directo e indirecto (combinando las dos frecuencias) alcanza el 31\% y el dizque como marcador de la fuente ajena e imprecisa alcanza el 26\%, lo cual ubica estas funciones entre las principales de este evidencial, en la misma vía en que lo reporta Travis (2006). Sin embargo, el hecho de que casi la mitad de los usos de dizque en Medellín no sean reportativos puede indicar que la tendencia de uso estrictamente evidencial tal vez está retrocediendo frente a otros usos, principalmente el epistémico, tal como se ha reportado en otros dialectos, especialmente el mexicano, y que De la Mora y Maldonado (2015) han expuesto claramente.

Además, en la descripción del corpus analizado en este trabajo se encontró una función evidencial de dizque que no se reporta en los otros estudios, esta corresponde al valor de marcador del modo de acceso cognitivo a la información, que aparece en las narraciones de sueños, con un 5\% del total de las ocurrencias de dizque en el corpus. La existencia de esta función refuerza el hallazgo hecho en otros dialectos de que dizque históricamente ha adquirido otros valores diferentes a los reportativos, incluso hasta el punto de remplazarlos por valores epistémicos. Esto indicaría que el dialecto de Medellín parece seguir una orientación similar.

Todo lo anterior evidencia la polifuncionalidad de dizque en el español de Medellín, en el cual se encuentran seis funciones para esta estrategia evidencial, que se enumeran en orden descendente de frecuencia a continuación: marcador de la fuente de información como ajena e imprecisa (26\%), marcador de modalidad epistémica (21\%), introductor de discurso directo (21\%), marcador de elementos nominales (17\%), introductor de discurso indirecto (10\%) e indicador de modo de acceso cognitivo a la información (5\%). La baja frecuencia de la función de modo de acceso cognitivo se debe a que solo aparece en relatos de sueños, que responden a una de las preguntas de la entrevista y en algunos casos esta pregunta no se formula. Es Ilamativo el hecho de que la función de introducción de discurso indirecto es mucho menor - poco menos de la mitad - que la de discurso directo, lo cual se explicaría porque (como lo 
han mostrado algunos estudios: San Martín y Guerrero, 2013) cuando los hablantes reproducen el discurso propio o ajeno de otras situaciones comunicativas, prefieren hacerlo más de forma directa que de forma indirecta. También es interesante la alta frecuencia de la función de marcación de elementos nominales, descrita en otros estudios, como el de Travis (2006) y el de De la Mora y Maldonado (2015), lo cual podría indicar que hay una tendencia del español colombiano que coincide con el proceso de cambio que se ha registrado para esta unidad en diferentes dialectos. Obviamente, esto tendría que ser corroborado en el futuro, a partir de otros estudios de variedades de habla de Colombia con corpus orales. Estos estudios también permitirían verificar la afirmación intuitiva de muchos hablantes de que el uso de dizque es mucho más frecuente en esta zona del país que en otras.

En cuanto a los resultados del análisis del uso de dizque en relación con las variables sociales, como se pudo observar, la única diferencia estadísticamente significativa que se encontró fue la referida al género, variable con respecto a la cual se estableció que las mujeres usan menos que los hombres esta unidad. Es difícil extraer consecuencias de estos datos, sobre todo teniendo en cuenta las dificultades existentes para tratar de explicar resultados de este tipo, como son la influencia de los prejuicios lingüísticos y sexistas, así como la forma poco satisfactoria como se abordan este tipo de explicaciones, tal como lo ha señalado Romaine (1994) a propósito de este tema. Sin embargo, con mucha cautela, se pueden apuntar algunas ideas sobre el significado que puede tener esta diferencia con respecto al uso de dizque.

Múltiples estudios sociolingüísticos (Romaine, 1994; Silva-Corvalán, 2001; Coates, 2009), en diferentes lenguas, han mostrado que las mujeres tienden a usar más formas lingüísticas estándar o prestigiosas que los hombres. En lo que difieren estos estudios es en las razones a las cuales atribuyen esta realidad: mayor conciencia de estatus por parte de la mujer, más preocupación por la cortesía, que tienden a ser más conservadoras, etc. Incluso en el mundo hispánico (Blas Arroyo, 2008) es recurrente que en muchas comunidades de habla se reporten hechos sociolingüísticos como la mayor aptitud lingüística de las mujeres, su mayor control sobre los registros y estilos comunicativos o su inclinación hacia el cultivo de las normas de prestigio suprarregionales en mayor medida que los hombres. Todo esto apunta a que las mujeres son particularmente sensibles a los fenómenos lingüísticos cuyo prestigio (o desprestigio) se manifiesta abiertamente, especialmente en las situaciones más formales (Blas Arroyo, 2008).

Para Silva-Corvalán (2001) el hecho de que las mujeres usen las variantes lingüísticas de mayor prestigio con más frecuencia que los hombres está relacionado con la hipercorrección en contextos formales, con la consideración del habla femenina como más conservadora, así como con su evaluación como más correcta, y con lo que ella denomina el "doble estándar" que se le aplica a las mujeres, cuyo comportamiento se espera que sea más cortés y más correcto y ajustado a las reglas impuestas por la sociedad. 
Por el contrario, Coates (2009) sostiene que estas diferencias encontradas entre hombres y mujeres no indican el carácter conservador del habla de las mujeres, pues la evidencia sociolingüística muestra que tanto hombres como mujeres originan cambios lingüísticos. Para esta autora, esta diferencia debe pensarse más en términos de la distinción entre los cambios conscientes, iniciados por las mujeres y que tienden hacia la norma de prestigio, y cambios inconscientes, originados por los hombres y que tienden a alejarse de la norma aceptada. Así, la autora concluye su argumentación con la observación de que el cambio es introducido tanto por hombres como por mujeres, pero en direcciones opuestas: Ias innovaciones femeninas se acercan a la norma de prestigio y las masculinas se alejan de ella.

De lo anterior se desprende que si las mujeres promueven o favorecen el uso de una forma lingüística en un contexto determinado, específicamente en un contexto formal, es porque en la comunidad esa forma se evalúa de manera positiva, o por lo menos su uso en dicho contexto. Y también, en el sentido inverso, se puede decir que si las mujeres usan menos una forma lingüística en un contexto formal se debe a que esa forma lingüística, o su realización en ese contexto, se evalúa como negativa en la comunidad de habla.

Esto último es lo que parece ocurrir con el uso de dizque en el español de Medellín. Teniendo en cuenta que el corpus con el que se trabajó se recogió a través de una entrevista semidirigida, estrategia que constituye una situación semiformal, en la cual el entrevistador es un desconocido para el informante, y a aquel se le indicó que hiciera las preguntas usando la forma de tratamiento pronominal usted — una forma más distante y formal_, se puede colegir que el estilo de habla está más cercano al registro formal que al informal —aunque al final de las entrevistas en general el habla sea un poco más fluida y espontánea-. En estas condiciones, se espera que se favorezca la aparición de formas lingüísticas propias del registro formal y que aparezcan menos aquellas asociadas a un estilo informal. Y si, además de esto último, las mujeres usan más o menos algunas formas lingüísticas en comparación con los hombres, también se podría establecer si esas formas se valoran de manera positiva o negativa en este contexto, apoyando esta inferencia en la conciencia que se le atribuye a las mujeres sobre la valoración social del prestigio de los fenómenos lingüísticos. Por lo tanto, si las mujeres usan menos que los hombres la estrategia evidencial dizque en este corpus, es probable que se deba a que en la comunidad de habla se considera más una forma propia del registro informal.

Esta inferencia parece reforzarse por los resultados obtenidos en relación con las variables de clase social y de nivel educativo - aunque en ellas no haya diferencias estadísticamente significativas, sí se pueden apreciar algunas tendencias-. Como se pudo observar en el apartado sobre el análisis cuantitativo del uso de dizque en relación con las variables sociales, esta estrategia evidencial la tienden a usar menos los informantes de clase social alta y de nivel educativo superior. Para Silva-Corvalán (2001) las variables clase social y de nivel educativo están estrechamente relacionadas (en la medida en que la pertenencia a una 
clase social suele estar asociada a una escolaridad determinada) y son las que para ella mejor predicen las características lingüísticas de una muestra en términos de la pertenencia a un grupo socioeconómico. Esto se debería a que el sistema educativo crea conciencia lingüística mediante la enseñanza de reglas prescriptivas y la corrección abierta de rasgos lingüísticos de poco prestigio; además, de acuerdo con la autora, la exposición extensa y continuada a la lengua escrita estándar y normalizada de los textos de estudio, y otros documentos, facilita la autocorrección, tanto así que, siguiendo a Silva-Corvalán (2001), los hablantes pueden llegar a suprimir o producir menos frecuentemente una forma lingüística de poco prestigio.

Estas indicaciones de que dizque es una estrategia evidencial propia del registro informal va en la misma vía de lo que Olbertz (2007) ya había afirmado en su estudio sobre esta unidad, en el que sostiene que el uso de dizque en el español mexicano no está marcado socialmente, sino más bien con respecto al registro, ya que aparece sobre todo en contextos informales.

Esto también concuerda con los datos del Corpus del español del siglo XXI (CORPES XXI), de la Real Academia Española, en el que se encuentran 433 realizaciones de dizque en 243 documentos (datos que proporciona el corpus automáticamente), y su frecuencia, de acuerdo con el tipo de texto en el que aparece, es la observada en el Gráfico 13:

\section{GRÁFICO 1}

Frecuencia de uso de dizque según tipo de texto (CORPES XXI)

\begin{tabular}{|lrr|}
\hline Tipología & Freq & Fnorm. \\
Ficción & 294 & 5,44 \\
\hline Crónica & 5 & 23,49 \\
\hline Biografia memoria & 4 & 11,77 \\
\hline Opinión & 2 & 2,34 \\
\hline Académico & 1 & 0,19 \\
\hline Reportaje & 1 & 0,35 \\
\hline Editorial & 1 & 18,58 \\
\hline $1-7$ de 7 & & página: 1 \\
\hline
\end{tabular}

3 Estos datos los proporciona el corpus automáticamente. No queda claro por qué la discordancia entre la frecuencia absoluta total y la suma de las frecuencias absolutas que aparecen en las tablas. Al parecer, los casos faltantes en la tabla se incluyen en la categoría "Otros" que no se registra en las tablas pero que sí aparece en las gráficas que arroja la página del corpus. Freq= frecuencia absoluta; Fnorm= frecuencia normalizada de casos por cada millón. 
Como se puede ver, dizque aparece, con una enorme diferencia con respecto a los otros, en los textos de ficción, que tal vez se aproximen más al habla oral cotidiana, mientras que en los otros tipos de textos, más alejados de la oralidad y que son de un carácter más formal —como lo son los textos de opinión, los académicos y los editoriales-, prácticamente no aparece esta estrategia evidencial.

Específicamente para el español colombiano, para el que aparecen 123 realizaciones en 53 documentos en este mismo corpus (CORPES XXI), se cumple la misma tendencia, tal como se puede observar en el Gráfico 2.

\section{GRÁFICO 2}

Frecuencia de uso de dizque en Colombia según tipo de texto (CORPES XXI)

\begin{tabular}{|lrr|}
\hline Tipología & Freq & Fnorm. \\
\hline Ficción & 95 & 1,75 \\
\hline Biografía memoria & 4 & 11,77 \\
\hline Opinión & 1 & 1,17 \\
\hline 1 - 3 de 3 & & página: 1
\end{tabular}

Aquí también se puede ver que, en el español colombiano, dizque aparece con mucha mayor frecuencia en los textos de ficción que en otros de carácter más formal como los de opinión.

Esta misma tendencia se observa en el Corpus de referencia del español actual (CREA), en el cual aparecen 265 casos de dizque en 116 documentos, de los cuales el $67.16 \%$ están en textos sobre ficción, muy por encima de la realización en textos sobre política, economía, comercio y finanzas (10.94\%), así como de otros sobre ciencias sociales, creencias y pensamiento (10.56\%), todos ellos más de carácter académico o especializado. Y en el caso del español colombiano, para el cual aparecen 37 casos de dizque en 17 documentos, también se mantiene la tendencia con respecto a estos tipos de textos, pues en los textos de ficción es más frecuente este evidencial que en los otros dos grupos de textos, con un $45.94 \%$, 27.02\% y $13.51 \%$, respectivamente.

En esta misma vía, los datos tomados de dos revistas académicas publicadas en MedeIlín, Lingüística y Literatura y Estudios de Literatura Colombiana, de las cuales se tomaron 20 artículos de investigación (10 de cada una) de autores colombianos, con un total de 144.743 palabras, muestran que no aparece la palabra dizque en estos textos. Teniendo en cuenta que el artículo de investigación es un tipo de texto absolutamente formal, estos resultados muestran que en este tipo de textos no se utiliza la unidad dizque. 
En suma, el hecho de que dizque se use con mucha menor frecuencia en textos formales y que las mujeres usen menos esta unidad en el corpus analizado indica que esta unidad se valora como poco prestigiosa en los contextos formales o semiformales (como es el caso de la entrevista semidirigida), lo cual concuerda con otras conclusiones que se han establecido en otros estudios con respecto a las diferencias de género en el habla, los estudios sobre dizque en otras variedades de habla, específicamente en el español mexicano, y los datos contenidos en otros corpus sobre el español en general y el español colombiano.

\section{Conclusión}

En el español de Medellín dizque tiene seis funciones: indicación de modalidad epistémica, fuente ajena imprecisa, discurso directo, discurso indirecto, marcación de elementos nominales y la indicación de modo de acceso cognitivo a la información que se presenta. En general, dizque tienden a usarlo menos las mujeres, los informantes de clase social alta y los de nivel educativo superior, lo cual está relacionado con que esta estrategia evidencial se considere más propia del registro informal.

En caso de hacerse estudios posteriores con corpus obtenidos en contextos más informales, probablemente se encuentre una frecuencia mayor de la ocurrencia de dizque y tal vez aparezcan otras funciones adicionales.

\section{Bibliografía citada}

Aikhenvald, Alexandra, 2006: Evidentiality, Oxford: Oxford University Press.

AndRade, Ricardo, María Claudia GonzÁlez y David JaRamillo, 2008: “La representatividad poblacional en el estudio sociolingüístico de Medellín”, Lenguaje 36 (2), 527-549.

Bermúdez, Fernando, 2006: Evidencialidad. La codificación lingüística del punto de vista, Estocolmo: Universidad de Estocolmo, Departamento de Español, Portugués y Estudios Latinoamericanos.

Blas Arroyo, José Luis, 2008: Sociolingüística del español. Desarrollos y perspectivas en el estudio de la lengua española en contexto social, Madrid: Cátedra.

CoAtes, Jennifer, 2009: Mujeres, hombres y lenguaje. Un acercamiento sociolingüístico a las diferencias de género, México: Fondo de Cultura Económica.

De La Mora, Juliana, y Ricardo Maldonado, 2015: “Dizque: Epistemics blurring evidentials in Mexican Spanish", Journal of Pragmatics 85, 168-180. 
García FajARdo, Josefina, 2009: "El modal dizque: estructura dinámica de sus valores semánticos" en Martha Islas (comp.): Entre las lenguas indígenas, la sociolingüística y el español, Muenchen: LINCOM, 302-325.

González Rátiva, María Claudia, 2007: "PRESEEA-Medellín-Co. Informe sobre el estado de la investigación" en Francisco Moreno Fernández y otros (eds.): El español hablado en las comunidades hispánicas. Informe PRESEEA 2007, Santander: Fundación Campus Comillas.

Gonzalez Rátiva, María Claudia, y Róbinson Grajales Alzate, 2011: "La clase social en el Corpus PRESEEA-Medellín”, Lenguaje 39 (1), 41-64.

LANDABURu, Jon, 2005: "Expresión gramatical de lo epistémico en algunas lenguas del norte de Suramérica” [http://lanic.utexas.edu/project/etext/liilas/cilla/landaburuz.pdf, fecha de consulta: 4 de septiembre de 2014].

Magaña, Elsie, 2005: “El paso de 'dice que' a 'dizque', de la referencia a la evidencialidad”, Contribuciones desde Coatepec 008, 59-70.

Miglıo, Viola, 2010: "Online databases and language change: The Case of Spanish dizque" en Stefan Th. Gries, Stefanie Wulff y Mark Davies (eds.): Corpus Linguistics Applications: Current Studies, New Directions (Language and Computer Series), Amsterdam: Rodopi.

Olbertz, Hella, 2005: "Dizque en el español andino ecuatoriano: conservador e innovador" en Hella Olbertz y Pieter MuYsken (eds.): Encuentros y conflictos: bilingüismo y contacto de lenguas en el mundo andino, Madrid/Frankfurt: Iberoamericana/Vervuert.

Olbertz, Hella, 2007: "Dizque in Mexican Spanish. The subjectification of reportative meaning", Rivista di Linguistica 19 (1), 151-172.

PRESEEA, 2003: "Metodología del Proyecto de Estudio sociolingüístico del Español de España y América (PRESEEA)" [http://preseea.linguas.net/Portals/o/Metodologia/ METODOLOG\%C3\%8DA\%20PRESEEA.pdf, fecha de consulta: 4 de enero de 2014].

Real Academia Española: Corpus del español del siglo XXI, "Banco de datos (CORPeS XXI)" [http://www.rae.es, fecha de consulta: 30 de noviembre de 2014].

Real Academia Española: Corpus de referencia del español actual, "Banco de datos (CREA)" [http://www.rae.es, fecha de consulta: 30 de noviembre de 2014].

Real Academia Española, 2001 : Diccionario de la lengua española. Madrid: Espasa

Romaine, Suzanne, 1994 : El lenguaje en la sociedad. Una introducción a la sociolingüística, Barcelona: Ariel.

San Martín, Abelardo, y Silvana Guerrero, 2013: "Una aproximación sociolingüística al empleo del discurso referido en el corpus PRESEEA de Santiago de Chile”, Signos 46 (82), 258-282. 
Silva-Corvalán, Carmen, 2001: Sociolingüística y pragmática del español, Washington: Georgetown University Press.

Travis, Catherine, 2006: "Dizque: a Colombian evidentiality strategy", Linguistics 44 (6), 1269-1297. 